UDC 517.929.4

Вестник СПбГУ. Прикладная математика. Информатика... 2019. Т. 15. Вып. 2

MSC 74G55

\title{
Stabilization of weak solutions of parabolic systems with distributed parameters on the graph
}

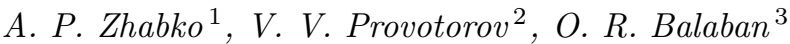

1 St. Petersburg State University, 7-9, Universitetskaya nab., St. Petersburg, 199034, Russian Federation

2 Voronezh State University, 1, Universitetskaya pl., Voronezh, 394006, Russian Federation

3 Air Force Academy named after professor N. E. Zhukovsky and Y. A. Gagarin, 54a, ul. Starikh Bol'shevikov, Voronezh,

396064, Russian Federation

For citation: Zhabko A. P., Provotorov V. V., Balaban O. R. Stabilization of weak solutions of parabolic systems with distributed parameters on the graph. Vestnik of Saint Petersburg University. Applied Mathematics. Computer Science. Control Processes, 2019, vol. 15, iss. 2, pp. 187-198. https://doi.org/10.21638/11702/spbu10.2019.203

In many applications because of the complexity of the mathematical models have to abandon the use of ordinary differential equations in behalf of considering the evolutionary equations with partial derivatives. In addition, most commonly the evolutionary problem study on the finite interval changes of a temporary variable. In practice, where you can solve the problem for arbitrary finite interval changes to a temporary variable it is important to know the behavior of the solution where, when the temporary variable strives to infinity. First of all, this is related to the study of the properties of the stability of the indicated solution and the possibility of constructing the stabilizing control in case of the instability. Precisely this case is the object of the study in this work, in which represent the analysis of the stability of the weak solutions of the evolutionary systems with distributed parameters on the graph with the unlimited growth of the temporary variable, obtain the conditions of the stabilization of the weak solutions. By studying the relevant initial-boundary value problem, we to be beyond the scope of the classical solutions and appeal to the weak solutions of the problem, reflecting more accurately the physical essence of appearance and processes (i. e. consider the initial-boundary value problem in weak formulation). In this case, the choice of the class of weak solutions to be determined one way or the other functional space is at the disposal of the researchers and to meet the demand, above all, conservation of the existence theorems and the uniqueness theorems for the arbitrary finite interval changes to a temporary variable. The fundamental used tool is the representation of a weak solution in the form of a functional series (method Faedo-Galerkin approximation with the special basis-system functions - the eigenfunction system) and the compactness of a many of approximate solutions (thanks to a priori estimates).

Keywords: an evolutionary system of parabolic type, distributed parameters on the graph, a weak solution, stabilization of a weak solution.

Introduction. Today have a lot of the results by analyze of the behavior of the solutions of the differential equations (the equations systems) to infinity, but, as we know, all they oriented of the ordinary differential equations and systems $[1,2]$. In many applications because of the complexity of the mathematical models have abandon to these differential systems in behalf of considering the evolutionary equations with partial derivatives. Precisely this case is the subject of study in this work: make attempt to analyze of the possibility of the stabilization solutions for the evolutionary systems with

(c) Санкт-Петербургский государственный университет, 2019 
distributed parameters on the graph. By studying the relevant initial-boundary value problem, we to by beyond the scope a classical solutions and reduce to the weak solutions of the problem (i. e. consider the initial-boundary value problem in weak formulation). These solutions describe more exactly the physical essence of phenomena and processes. In this case, the choice of the class of weak solutions to be determined one way or the other functional space, to meet the demand, above all, conservation of the existence theorems and the uniqueness theorems for the arbitrary finite interval changes to a temporary variable (provided that correspond to the spirit of the study phenomenon or processes). The fundamental used tool is the representation of a weak solution in the form of a functional series (method Faedo-Galerkin approximation with the special basis-system functions - the eigenfunction system) and the compactness of a many of approximate solutions (thanks to a priori estimates).

Basic concepts and notation. In the paper considers the question of stabilizing the weak solving of the problem

$$
\frac{\partial u(x, t)}{\partial t}+\mathbb{A} u=f(x, t), \quad u(x, 0)=\varphi(x),
$$

when $t \rightarrow \infty$ for the evolutionary system of parabolic equations with distributed parameters on the graph $\Gamma$ (in the applications - on the network) [3-6] (for hyperbolic systems see the paper [7]) and what role is played by the operator $\mathbb{A}$. In here $\mathbb{A}$ is the positive definite operator with discrete spectrum, acting in a Hilbert space $H, f(x, t)$ and $u(x, t)$ are the specified and search abstract functions with values in the same space $H$ (the map $t \rightarrow H), \varphi(x)$ is the element of the space $L_{2}(\Gamma)$. Weak solution (1) is defined as the map $t \rightarrow H$, satisfying a integral identity [5,6]. In particular get the conditions, fulfill under which a weak solution of problem (1) converges for $t \rightarrow \infty$ in norm $H$ to a some weak solution $v \in W \subset H$ of problem

$$
\mathbb{A} v=g, \quad g \in H .
$$

We introduce the following concepts and symbols adopted in the works $[5,6]$ :

- $\Gamma$ is the limited oriented geometric graph with edges $\gamma$, parameterized the segment $[0,1]$;

- $\partial \Gamma$ and $J(\Gamma)$ are the many of boundary $\zeta$ and internal $\xi$ nodes of graph respectively;

$-\Gamma_{0}$ is the join of all the edges of the graph $\Gamma$, does not contain the endpoints;

$-\Gamma_{t}=\Gamma_{0} \times(0, t)\left(\gamma_{t}=\gamma_{0} \times(0, t)\right), \partial \Gamma_{t}=\partial \Gamma \times(0, t)(t \in(0, T], T<\infty)$.

All through of the work make use of the classic space of functions:

- $L_{p}(\Gamma)(p=1,2)$ is a Banach space of measurable functions on $\Gamma_{0}$, integrable with degree of order $p$ (similarly defined the space $L_{p}\left(\Gamma_{T}\right)$ );

$-L_{2,1}\left(\Gamma_{T}\right)$ is the space of functions from $L_{1}\left(\Gamma_{T}\right),\|u\|_{L_{2,1}\left(\Gamma_{T}\right)}=\int_{0}^{T}\left(\int_{\Gamma} u^{2} d x\right)^{\frac{1}{2}} d t$.

As well we make use of the analogues of Sobolev spaces $[8,9]$ :

- $W_{2}^{1}(\Gamma)$ is the space of functions from $L_{2}(\Gamma)$, with generalized derivative of order 1 also from $L_{2}(\Gamma)$;

- $W_{2}^{1,0}\left(\Gamma_{T}\right)$ is the space of functions from $L_{2}\left(\Gamma_{T}\right)$ with generalized derivative of order 1 for $x$ belonging to space $L_{2}\left(\Gamma_{T}\right)$ (similarly defined the space $W_{2}^{1}\left(\Gamma_{T}\right)$ );

$-V_{2}\left(\Gamma_{T}\right)$ is the set of all functions $u(x, t) \in W_{2}^{1,0}\left(\Gamma_{T}\right)$ with finite norm

$$
\|u\|_{2, \Gamma_{T}} \equiv \max _{0 \leqslant t \leqslant T}\|u(\cdot, t)\|_{L_{2}(\Gamma)}+\left\|u_{x}\right\|_{L_{2}\left(\Gamma_{T}\right)}
$$

these functions are continuous on $t$ in norm space $L_{2}(\Gamma)$. 
We will introduce the state space of parabolic system and the auxiliary space. Consider the bilinear form

$$
\ell(\mu, \nu)=\int_{\Gamma}\left(a(x) \frac{d \mu(x)}{d x} \frac{d \nu(x)}{d x}+b(x) \mu(x) \nu(x)\right) d x
$$

with a fixed measurable and limited on $\Gamma_{0}$ functions $a(x), b(x)$ square integrable.

If the function $u(x) \in W_{2}^{1}(\Gamma)$ и $\ell(u, \nu)-\int_{\Gamma} f(x) \nu(x) d x=0$ for any $\nu(x) \in W_{2}^{1}(\Gamma)$ $\left(f(x) \in L_{2}(\Gamma)\right.$ is the fixed function), then (lemma 2 in [10, p. 92]) for any edge $\gamma \subset \Gamma$ the narrowing of the function $a(x)_{\gamma} \frac{d u(x)_{\gamma}}{d x}$ continuously in the endpoints of the edge $\gamma$. Relabel $\Omega_{a}(\Gamma)$ the many of these functions $u(x)$ satisfying the ratios $\sum_{\gamma \in R(\xi)} a(1)_{\gamma} \frac{d u(1)_{\gamma}}{d x}=$ $\sum_{\gamma \in r(\xi)} a(0)_{\gamma} \frac{d u(0)_{\gamma}}{d x}$ in all nodes $\xi \in J(\Gamma)$ (in here $R(\xi)$ and $r(\xi)$ is the sets of the edges $\gamma$ accordingly oriented "to node $\xi$ " and "from node $\xi$ ") and $\left.u(x)\right|_{\partial \Gamma}=0$. The closing of the set $\Omega_{a}(\Gamma)$ in norm $W_{2}^{1}(\Gamma)$ relabel $W_{0}^{1}(a, \Gamma)$.

Let the next $\Omega_{a}\left(\Gamma_{T}\right)$ are the set of functions $u(x, t) \in V_{2}\left(\Gamma_{T}\right)$, whose traces are defined in sections of the domain $\Gamma_{T}$ the plane $t=t_{0}\left(t_{0} \in[0, T]\right)$ as a function of class $W_{0}^{1}(a, \Gamma)$ and satisfy a ratios

$$
\sum_{\gamma \in R(\xi)} a(1)_{\gamma} \frac{\partial u(1, t)_{\gamma}}{\partial x}=\sum_{\gamma \in r(\xi)} a(0)_{\gamma} \frac{\partial u(0, t)_{\gamma}}{\partial x}
$$

for all nodes $\xi \in J(\Gamma)$. The closing of the set $\Omega_{a}\left(\Gamma_{T}\right)$ in norm (3) relabel $V^{1,0}\left(a, \Gamma_{T}\right)$; it is clear that $V^{1,0}\left(a, \Gamma_{T}\right) \subset W_{2}^{1,0}\left(\Gamma_{T}\right)$.

Another the subspace of the space $W_{2}^{1,0}\left(\Gamma_{T}\right)$ is $W^{1}\left(a, \Gamma_{T}\right)$, i. e. is the closing in norm $W_{2}^{1}\left(\Gamma_{T}\right)$ the set of differentiable on $\Gamma_{0}$ functions $u(x, t)$ satisfy a ratios (4) for all nodes $\xi \in J(\Gamma)$ and boundary condition $\left.u(x, t)\right|_{\partial \Gamma}=0$ for any $t \in[0, T]$ (the derivatives in the nodes are defined as the one-sided derivative).

Remark 1. The space $V^{1,0}\left(a, \Gamma_{T}\right)$ describes the states set of parabolic system (1), $W^{1}\left(a, \Gamma_{T}\right)$ is the auxiliary space; $H=L_{2}(\Gamma), W=W_{0}^{1}(a, \Gamma), \mathbb{A} y=-\frac{d}{d x}\left(a(x) \frac{d y(x)}{d x}\right)+$ $b(x) y(x)$.

In the space $V^{1,0}\left(a, \Gamma_{T}\right)$ considered the parabolic equation

$$
\frac{\partial y(x, t)}{\partial t}-\frac{\partial}{\partial x}\left(a(x) \frac{\partial y(x, t)}{\partial x}\right)+b(x) y(x, t)=f(x, t),
$$

represents a system of differential equations with distributed parameters on each edge $\gamma$ of the graph $\Gamma ; f(x, t) \in L_{2,1}\left(\Gamma_{T}\right)$. The state $y(x, t)\left(x, t \in \bar{\Gamma}_{T}\right)$ of the system (5) in the domain $\bar{\Gamma}_{T}$ is determined by a weak solution $y(x, t)$ of the equation (5), satisfying the initial and boundary conditions

$$
\left.y\right|_{t=0}=\varphi(x), \quad x \in \Gamma,\left.\quad y\right|_{x \in \partial \Gamma_{T}}=0,
$$

$\varphi(x) \in L_{2}(\Gamma)$. The assumptions about the functions $a(x)$ and $b(x)$ to make mention above. From $y(x, t) \in V^{1,0}\left(a, \Gamma_{T}\right)$ should be noted, that the map $y:[0, T] \rightarrow W_{0}^{1}(a, \Gamma) \subset L_{2}(\Gamma)$ is a continuous function, so that the first equality (6) makes sense and is be understood almost everywhere. 
Definition. A weak solution of the initial-boundary value problem (5), (6) is the function $y(x, t) \in V^{1,0}\left(a, \Gamma_{T}\right)$, that satisfies an integral identity

$$
\begin{gathered}
\int_{\Gamma} y(x, t) \eta(x, t) d x-\int_{\Gamma_{t}} y(x, t) \frac{\partial \eta(x, t)}{\partial t} d x d t+\ell_{t}(y, \eta)= \\
=\int_{\Gamma} \varphi(x) \eta(x, 0) d x+\int_{\Gamma_{t}} f(x, t) \eta(x, t) d x d t
\end{gathered}
$$

for any function $\eta(x, t) \in W^{1}\left(a, \Gamma_{T}\right)$ and for any $t \in[0, T]$.

The necessary approval. Let's give the necessary approval, the full proof which are presented in the works [3-6].

In proving solvability the problem (5), (6) in the space $V^{1,0}\left(a, \Gamma_{T}\right)$ make use a special basis of space $W_{0}^{1}(a, \Gamma)$ - the system of generalized eigenfunctions of boundary-value problem on the eigenvalues (the spectral problem)

$$
-\frac{d}{d x}\left(a(x) \frac{d u(x)}{d x}\right)+b(x) u(x)=\lambda u(x),\left.\quad u(x)\right|_{\partial \Gamma}=0
$$

in the classroom $W^{1}(a, \Gamma)$ [10, p. 106; 11]. This problem consists in finding many such numbers $\lambda$ (the eigenvalues of the boundary value problem (7)), each of which corresponds to at least one nontrivial generalized solution $u(x) \in W_{0}^{1}(a, \Gamma)$ (the generalized eigenfunctions), satisfies the integral identity

$$
\ell(u, \eta)=\lambda(u, \eta)
$$

for any function $\eta(x) \in W_{0}^{1}(a, \Gamma)$ (here and everywhere below through $(\cdot, \cdot)$ designated the scalar product in $L_{2}(\Gamma)$ or $\left.L_{2}\left(\Gamma_{T}\right)\right)$.

Install the necessary further the properties of eigenvalues and eigenfunctions of the generalized spectral problem (7). To do this, we will introduce in the space $W_{0}^{1}(a, \Gamma)$ of new the scalar product

$$
[u, v]=\int_{\Gamma}\left(a(x) \frac{d u(x)}{d x} \frac{d v(x)}{d x}+\left(\lambda_{0}+b(x)\right) u(x) v(x)\right) d x=\ell(u, v)+\lambda_{0}(u, v),
$$

where the number $\lambda_{0}$ of determined inequality $\lambda_{0}>\beta$ (here the constant $\beta$ fixed the condition of the restriction to functions $b(x):|b(x)| \leqslant \beta)$. Then given (2) true the ratio

$$
[u, v] \geqslant a_{*}\left\|\frac{d u}{d x}\right\|^{2}+\left(\lambda_{0}-\beta\right)\left\|\frac{d v}{d x}\right\|^{2} \geqslant \alpha\left(\left\|\frac{d u}{d x}\right\|^{2}+\left\|\frac{d v}{d x}\right\|^{2}\right),
$$

$\alpha>0$ is the fixed constant. The latter means equivalence of norms $\|u\|_{[\cdot, \cdot]}=\sqrt{[u, u]}$ created by the scalar product $[\cdot, \cdot]$ and the norm $\|u\|_{W_{2}^{1}(\Gamma)}$ of space $W_{0}^{1}(a, \Gamma)$. The generalized eigenfunctions of the spectral problem (7) satisfy the integral identity

$$
[u, \eta]=\left(\lambda_{0}+\lambda\right)(u, \eta)
$$

for any function $\eta(x) \in W_{0}^{1}(a, \Gamma)$.

In the space $W_{0}^{1}(a, \Gamma)$ we define the operator $B$ by using identities

$$
[B u, \eta]=(u, \eta) \quad \forall \eta(x) \in W_{0}^{1}(a, \Gamma),
$$

after which the identity (9) is equivalent to

$$
[B u, \eta]=\tilde{\lambda}[u, \eta] \quad \forall \eta(x) \in W_{0}^{1}(a, \Gamma),
$$


where $\tilde{\lambda}=1 /\left(\lambda_{0}+\lambda\right)$. It is easy to verify that the operator $B$ is completely continuous, selfadjoint and positive operator. Whence it follows that his the eigenvalues $\left\{\tilde{\lambda}_{i}\right\}_{i \geqslant 1}$ are real, positive and situated in the decrease order, taking into account their multiplicity, moreover $\tilde{\lambda}_{i} \rightarrow 0$ under $i \rightarrow \infty$. Note that the point $\tilde{\lambda}=0$ is not its eigenvalue, because under $\tilde{\lambda}=0$ from the definition of the operator $B$ it should by $u=0$. The generalized eigenfunctions $\left\{u_{i}(x)\right\}_{i \geqslant 1}$, relating to the eigenvalues $\left\{\tilde{\lambda}_{i}\right\}_{i \geqslant 1}$, are real and mutually orthogonal: $\left[u_{i}, u_{j}\right]=$ 0 under $i \neq j$. In view of the foregoing, the system of generalized eigenfunctions $\left\{u_{i}(x)\right\}_{i \geqslant 1}$ form a basis in space $W_{0}^{1}(a, \Gamma)$, as well $W_{0}^{1}(a, \Gamma)$ dense in $L_{2}(\Gamma)$, then $\left\{u_{i}(x)\right\}_{i \geqslant 1}$ is the basis in $L_{2}(\Gamma)\left(\left\{u_{i}(x)\right\}_{i \geqslant 1}\right.$ is the orthonormal basis in $\left.L_{2}(\Gamma)\right)$. Given the apparent relationship $\lambda_{i}=-\lambda_{0}+1 / \tilde{\lambda}_{i}$ of the eigenvalues $\lambda_{i}$ of the spectral problem (7) and the eigenvalues $\tilde{\lambda}_{i}$ of the operator $B$, as well as the match of the generalized eigenfunctions, come to the next approval.

Theorem 1. Let $0<a_{*} \leqslant a(x) \leqslant a^{*},|b(x)| \leqslant \beta, x \in \Gamma_{0}$. Then the spectral problem (7) has counted many the real eigenvalues $\left\{\lambda_{i}\right\}_{i \geqslant 1}$ (situated in the ascending order, taking into account their multiplicity), moreover $\lambda_{i} \rightarrow \infty$ under $i \rightarrow \infty$ (the eigenvalues $\lambda_{i}$ are positive, except maybe for a finite number of the first). System of the generalized eigenfunctions $\left\{u_{i}(x)\right\}_{i \geqslant 1}$ form a basis in $W_{0}^{1}(a, \Gamma)$ and $L_{2}(\Gamma)$. The generalized eigenfunctions orthonormalized in $L_{2}(\Gamma)$ and orthogonal in terms of the scalar product $[\cdot, \cdot \cdot]$.

Remark 2. If $0 \leqslant b(x) \leqslant \beta$, as is usually the case in the applications, then all eigenvalues of the spectral problem (7) is positive with limit point at infinity. Indeed, this follows from the integral identities (8), when $u=\eta=u_{i}(x), \lambda=\lambda_{i}$ and a chain of equalities

$$
\ell\left(u_{i}, u_{i}\right)=\lambda_{i}\left(u_{i}, u_{i}\right)=\lambda_{i}\left\|u_{i}\right\|^{2}=\lambda_{i}
$$

for $i=1,2, \ldots$ (see also [9, p. 98]). The positiveness of the eigenvalues is the determining factor for establishing the stability condition and the possibility of the stabilizing of evolutionary systems of parabolic equations with distributed parameters on the graph.

Remark 3. The operator $\mathbb{A}$ is the symmetric positive definite operator with discrete spectrum and operating in the space $W_{0}^{1}(a, \Gamma) \subset L_{2}(\Gamma)$ with the values in $L_{2}(\Gamma)$. The domain of definition is the set $\Omega_{a}(\Gamma)$, dense in the space $W_{0}^{1}(a, \Gamma)$.

A direct consequence arising from remarks 2 and 3 is (see [10, p. 105])

Theorem 2. The problem

$$
\mathbb{A} v \equiv-\frac{d}{d x}\left(a(x) \frac{d u(x)}{d x}\right)+b(x) u(x)=g, g \in L_{2}(\Gamma),
$$

has a unique weak solution in space $W_{0}^{1}(a, \Gamma)$.

Theorem 3. When any $f(x) \in L_{2,1}\left(\Gamma_{T}\right), \varphi(x) \in L_{2}(\Gamma)$ and for any $0<T<\infty$ the initial-boundary value problem (5), (6) has a unique weak solution in the space $V^{1,0}\left(a, \Gamma_{T}\right)$.

Under proof of the conclusion of theorem 3 make use of the Faedo-Galerkin method with the basis $\left\{u_{i}(x)\right\}_{i \geqslant 1}$ (theorem 1). A detailed proof represent in the work [12].

For simplicity, the further statement of change space $L_{2,1}\left(\Gamma_{T}\right)$, replacing this space on $C L_{2,1}\left(\Gamma_{T}\right) \subset L_{2,1}\left(\Gamma_{T}\right)\left(C L_{2,1}\left(\Gamma_{T}\right)\right.$ is the space of functions from $L_{2,1}\left(\Gamma_{T}\right)$, that are continuous on $t$ in the norm $L_{2}(\Gamma)$ ), when this $f(x, t) \in C L_{2,1}\left(\Gamma_{T}\right)$ (the latter is easy condition in applications). In this case, as shown in the work [12], the weak solution $y(x, t) \in V^{1,0}\left(a, \Gamma_{T}\right)$ of problem (5), (6) for any $0<T<\infty$ representable in the form of the series

$$
y(x, t)=\sum_{i=1}^{\infty}\left(\varphi_{i} e^{-\lambda_{i} t}+\int_{0}^{t} f_{i}(\tau) e^{-\lambda_{i}(t-\tau)} d \tau\right) u_{i}(x),
$$


where $\varphi(x)=\sum_{i=1}^{\infty} \varphi_{i} u_{i}(x) ; \varphi_{i}=\int_{\Gamma} \varphi(x) u_{i}(x) d x ; f(x, t)=\sum_{i=1}^{\infty} f_{i}(t) u_{i}(x) ; f_{i}(t)=$ $\int_{\Gamma} f(x, t) u_{i}(x) d x, \quad t \in[0, T]$.

In many applications, particularly, when studying conditions stabilize, where investigate the properties of solutions $y(x, t) \in V^{1,0}\left(a, \Gamma_{T}\right)$ of the problem (5), (6) for an arbitrary finite $T$, it is important to know $y(x, t)$ when $t \rightarrow+\infty$. To do this, let's consider a simple and unobtrusive enough condition for the existence in the domain $\Gamma_{\infty}=\Gamma_{0} \times[0, \infty)$ of the free member $f(x, t)$ of the equation (5) [12]. Namely, let any $T$, just as above, $f(x, t) \in C L_{2,1}\left(\Gamma_{T}\right)$, with

$$
\int_{t}^{t+1}\|f(\cdot, \varsigma)\|_{L_{2}(\Gamma)}^{2} d \varsigma \leqslant A
$$

for any $t \geqslant 0, A$ is the fixed constant (the ratio (12) indicates that the function $f(x, t)$ is defined and limited in the domain $\left.\Gamma_{\infty}\right)$.

Remark 4. To improve the properties of the function $f(x, t)$ on a variable $t$ level of smoothness of weak solutions $y(x, t)$ on $t>0$ (see remark 3 in the work [12]).

Indeed, let $f(x, t) \in C^{(1)}\left((0, \infty) ; L_{2}(\Gamma)\right)$ (in here $C^{(1)}\left((0, \infty) ; L_{2}(\Gamma)\right)$ is the maps space $f(x, t)$ from the variable $t$ with values in $L_{2}(\Gamma), f_{t}(x, t) \in L_{2}(\Gamma)$ for any $\left.t \in(0, \infty)\right)$. The series

$$
y_{t}(x, t)=\sum_{i=1}^{\infty}\left(-\lambda_{i} \varphi_{i} e^{-\lambda_{i} t}+f_{i}(t)-\lambda_{i} \int_{0}^{t} f_{i}(\tau) e^{-\lambda_{i}(t-\tau)} d \tau\right) u_{i}(x),
$$

received of differentiation (11) on $t$, converge in metric $L_{2}(\Gamma)$ uniformly along $t$ in any segment $\left[t_{0}, T\right], 0<t_{0}<T<\infty$. Indeed, if we take the integral by parts, we get the series with coefficients

$$
-\lambda_{i} \varphi_{i} e^{-\lambda_{i} t}+f_{i}(0) e^{-\lambda_{i} t}+\int_{0}^{t} f_{i}^{\prime}(\tau) e^{-\lambda_{i}(t-\tau)} d \tau .
$$

Evaluate these coefficients. Given the inequality of Cauchy, square coefficient, when random $i$ at is does not exceed the magnitude of

$$
\begin{gathered}
3 \varphi_{i}^{2}\left(\lambda_{i} e^{-\lambda_{i} t}\right)^{2}+3 f_{i}^{2}(0) e^{-2 \lambda_{i} t}+3\left(\int_{0}^{t} f_{i}^{\prime}(\tau) e^{-\lambda_{i}(t-\tau)} d \tau\right)^{2} \leqslant \\
\leqslant \frac{3}{t_{0}{ }^{2}} \varphi_{i}^{2}+3 f_{i}^{2}(0)+\frac{3}{2 \lambda_{i}} \int_{0}^{T}\left[f_{i}^{\prime}(\tau)\right]^{2} d \tau
\end{gathered}
$$

for any $T \in\left(t_{0}, \infty\right)$. On the assumptions about the functions $\varphi(x)$ and $f(x, t)$ should that a series with a total member of $\frac{3}{t_{0}{ }^{2}} \varphi_{i}^{2}+3 f_{i}^{2}(0)+\frac{3}{2 \lambda_{i}} \int_{0}^{T}\left[f_{i}^{\prime}(\tau)\right]^{2} d \tau$ converge, and it means that a series (13) converges uniformly on the metric $L_{2}(\Gamma)$ in any segment $\left[t_{0}, T\right]$, $0<t_{0}<T<\infty$. From this assertion should be the sum $y(x, t)$ of the series (11) belongs to the space $C^{(1)}\left((0, \infty) ; W^{1}(a, \Gamma)\right)$.

Theorem 4. Let $y(x, t) \in V^{1,0}\left(a, \Gamma_{T}\right)$ is a weak solution of problem (5), (6) for an arbitrary $T>0$ which $f(x, t)$, satisfies the condition (12). Then there is such positive constant $C$, that $\| y(\cdot, t)) \|_{L_{2}(\Gamma)} \leqslant C$ when $t \rightarrow+\infty$.

$\mathrm{P}$ r o o f. Split semiaxis $[0, \infty)$ into sections $[j-1, j], j=1,2, \ldots$, and relabel $t_{j}$ a number belonging to $[j-1, j]$, for which

$$
\left\|y\left(\cdot, t_{j}\right)\right\|_{L_{2}\left(\Gamma_{T}\right)}^{2}=\max _{t \in[j-1, j]}\|y(\cdot, t)\|_{L_{2}\left(\Gamma_{T}\right)}^{2}, \quad j=1,2, \ldots .
$$


For arbitrary positive $s$ and $t(s<t)$ from the integral identities of the define of weak problem solving (5), (6) should the ratio

$$
\begin{gathered}
\int_{s}^{t}\left(\frac{\partial y(x, t)}{\partial t}, y(x, t)\right) d t+\int_{s}^{t} \int_{\Gamma}\left(a(x) \frac{\partial y(x, t)}{\partial x} \frac{\partial y(x, t)}{\partial x}+b(x) y(x, t) y(x, t)\right) d x d t= \\
=\int_{s}^{t}(f(x, t), y(x, t)) d t
\end{gathered}
$$

if you put $\eta(x, t)=y(x, t)$ (ipso the remark 4 of theorem 3 the function $y(x, t)$ differentiable along $\left.t, \frac{\partial y(x, t)}{\partial t} \in L_{2}\left(\Gamma_{T}\right)\right)$. Of this ratio is obtained the inequality

$$
\begin{gathered}
\frac{1}{2}\|y(\cdot, t)\|_{L_{2}(\Gamma)}^{2}-\frac{1}{2}\|y(\cdot, s)\|_{L_{2}(\Gamma)}^{2}+\alpha \int_{s}^{t}\|y(\cdot, \varsigma)\|_{W_{2}^{1}(\Gamma)}^{2} d \varsigma \leqslant \\
\leqslant\left(\int_{s}^{t}\|f(\cdot, t)\|_{L_{2}(\Gamma)}^{2} d t\right)^{1 / 2}\left(\int_{s}^{t}\|y(\cdot, \varsigma)\|_{W_{2}^{1}(\Gamma)}^{2} d \varsigma\right)^{1 / 2},
\end{gathered}
$$

where the positive constant $\alpha$ depends only on fixed $a_{*}$ and $\beta_{*}$ (see the condition of theorem 1 and remark 2).

Further reasoning relies on the idea presented in the monograph by J.-L. Lions [13, p. 519]: use the inequality (15) for an arbitrary segment $\left[t_{j}, t_{j+2}\right], j=1,2, \ldots$, because when condition (14) makes it possible the equality $t_{j}=t_{j+1}$.

We show that for any $j=1,2, \ldots$

$$
\left\|y\left(\cdot, t_{j+2}\right)\right\|_{L_{2}(\Gamma)} \leqslant \max \left\{\left\|y\left(\cdot, t_{j}\right)\right\|_{L_{2}(\Gamma)}, M\right\},
$$

where $M=\left(\frac{3 A}{\alpha^{2}} \chi^{2}+\frac{6 A}{\alpha}\right)^{1 / 2} ; \chi$ is the inclusive constant the space $W_{2}^{1}(\Gamma)$ in $L_{2}(\Gamma)$.

1. Let $\left\|y\left(\cdot, t_{j+2}\right)\right\|_{L_{2}(\Gamma)} \leqslant\left\|y\left(\cdot, t_{j}\right)\right\|_{L_{2}(\Gamma)}$, then the proof is complete.

2. Suppose that

$$
\left\|y\left(\cdot, t_{j+2}\right)\right\|_{L_{2}(\Gamma)}>\left\|y\left(\cdot, t_{j}\right)\right\|_{L_{2}(\Gamma)} .
$$

By virtue of (15) for $s=t_{j}, t=t_{j+2}$ true the inequality

$$
\begin{gathered}
\frac{1}{2}\left\|y\left(\cdot, t_{j+2}\right)\right\|_{L_{2}(\Gamma)}^{2}+\alpha \int_{t_{j}}^{t_{j+2}}\|y(\cdot, \varsigma)\|_{W_{2}^{1}(\Gamma)}^{2} d \varsigma \leqslant \\
\leqslant \frac{1}{2}\left\|y\left(\cdot, t_{j}\right)\right\|_{L_{2}(\Gamma)}^{2}+\left(\int_{t_{j}}^{t_{j+2}}\|f(\cdot, \varsigma)\|_{L_{2}(\Gamma)}^{2} d \varsigma\right)^{1 / 2}\left(\int_{t_{j}}^{t_{j+2}}\|y(\cdot, \varsigma)\|_{W_{2}^{1}(\Gamma)}^{2} d \varsigma\right)^{1 / 2},
\end{gathered}
$$

whence, comparing (17) to (18) it should be

$$
\alpha\left(\int_{t_{j}}^{t_{j+2}}\|y(\cdot, \varsigma)\|_{W_{2}^{1}(\Gamma)}^{2} d \varsigma\right)^{1 / 2}<\left(\int_{t_{j}}^{t_{j+2}}\|f(\cdot, \varsigma)\|_{L_{2}(\Gamma)}^{2} d \varsigma\right)^{1 / 2}
$$

Taking into account $t_{j+2}-t_{j} \leqslant 3$ and the ratio $\int_{t}^{t+1}\|f(\cdot, \varsigma)\|_{L_{2}(\Gamma)}^{2} d \varsigma \leqslant A$, we obtain $\int_{t_{j}}^{t_{j+2}}\|f(\cdot, \varsigma)\|_{L_{2}(\Gamma)}^{2} d \varsigma \leqslant 3 A$ and the evaluation (19) takes a resultant form

$$
\int_{t_{j}}^{t_{j+2}}\|y(\cdot, \varsigma)\|_{W_{2}^{1}(\Gamma)}^{2} d \varsigma<\frac{3 A}{\alpha^{2}}
$$


Since $t_{j+2}-t_{j} \geqslant 1$, then exist $\tau \in\left[t_{j}, t_{j+2}\right]$ such that $\int_{t_{j}}^{t_{j+2}}\|y(\cdot, \varsigma)\|_{W_{2}^{1}(\Gamma)}^{2} d \varsigma=\left(t_{j+2}-\right.$ $\left.t_{j}\right)\|y(\cdot, \tau)\|_{W_{2}^{1}(\Gamma)}^{2} \geqslant\|y(\cdot, \tau)\|_{W_{2}^{1}(\Gamma)}^{2}$, it means, from the evaluation (20) it should be

$$
\|y(\cdot, \tau)\|_{L_{2}(\Gamma)} \leqslant \chi \sqrt{\frac{3 A}{\alpha^{2}}} .
$$

Let right how $s=\tau, t=t_{j+2}$ in the ratio (15), then using (20), come to the inequality

$$
\frac{1}{2}\left\|y\left(\cdot, t_{j+2}\right)\right\|_{L_{2}(\Gamma)}^{2} \leqslant \frac{1}{2}\|y(\cdot, \tau)\|_{L_{2}(\Gamma)}^{2}+(3 A)^{1 / 2}\left(\frac{3 A}{\alpha^{2}}\right)^{1 / 2},
$$

or, taking into account $(21)$,

$$
\frac{1}{2}\left\|y\left(\cdot, t_{j+2}\right)\right\|_{L_{2}(\Gamma)}^{2} \leqslant \frac{1}{2}\left(\chi \sqrt{\frac{3 A}{\alpha^{2}}}\right)^{2}+(3 A)^{1 / 2}\left(\frac{3 A}{\alpha^{2}}\right)^{1 / 2}=\frac{3 A}{\alpha^{2}} \chi^{2}+\frac{3 A}{\alpha},
$$

or

$$
\left\|y\left(\cdot, t_{j+2}\right)\right\|_{L_{2}(\Gamma)}^{2} \leqslant M^{2}=\frac{6 A}{\alpha^{2}} \chi^{2}+\frac{6 A}{\alpha} .
$$

From here and the assumption (17) it should be (16) and further to any $t>0$ the inequality $\| y(\cdot, t)) \|_{L_{2}(\Gamma)} \leqslant \max \left\{\max _{t \in[0,2]}\|y(\cdot, t)\|_{L_{2}(\Gamma)}, M\right\}=C$ is correctly. Thus, the assertion of the theorem is proved, the solution $y(x, t)$ defined in domain $\Gamma_{\infty}=\Gamma_{0} \times[0, \infty)$.

Corollary. In the conditions of theorems 3 and 4 the initial-boundary value problem (5), (6) is uniquely weakly solvable in space $V^{1,0}\left(a, \Gamma_{\infty}\right)$.

Remark 5. The conditions of theorem 4 allow another of importance fact. Applying (15) to $(t, t+1)$, get the inequality

$$
\alpha \int_{s}^{t}\|y(\cdot, \varsigma)\|_{W_{2}^{1}(\Gamma)}^{2} d \varsigma \leqslant \frac{1}{2} C^{2}+A^{1 / 2}\left(\int_{s}^{t}\|y(\cdot, \varsigma)\|_{W_{2}^{1}(\Gamma)}^{2} d \varsigma\right)^{1 / 2},
$$

from which should be the existence of a positive constant $C^{*}$ such that $\int_{t}^{t+1}\|y(\cdot, \varsigma)\|_{W_{2}^{1}(\Gamma)}^{2} d \varsigma \leqslant$ $\leqslant C^{*}$ for any $t \geqslant 0$.

Stabilization of weak solution. Suppose that $0 \leqslant b(x) \leqslant \beta$ for $x \in \Gamma_{0}$, then the eigenvalues $\lambda_{i}, i \geqslant 1$, are positive (remark 2). Consider the system (5) in the domain $\Gamma_{\infty}$. The right side $f(x, t)$ of the equation (5) is the distributed effect $v(x, t)=f(x, t)$ on the evolutionary system (5), (6). The function $v(x, t)$ belong to the class $C^{(1)}\left((0, \infty) ; L_{2}(\Gamma)\right)$ and satisfy the conditions of the theorems $1-4$.

Relabel $y(v ; x, t)$ the weak solution of initial-boundary value problem $(5),(6)$ under the condition $f(x, t)=v(x, t)$.

The problem of stabilize a weak solution. Solution $y(v ; x, t)$ of the system (5), (6) with the initial state $\varphi(x)$ using control effect $v(x, t)$ (further: the stabilizing control) is to definition such the conditions on the stabilizing control $v(x, t)$ and the function $\theta(x) \in W_{0}^{1}(a, \Gamma)$, that weak solution $y(v ; x, t)$ of the initial-boundary value problem (5), (6) strive to $\theta(x)$ under $t \rightarrow \infty$ in norm of the space $L_{2}(\Gamma)$.

Theorem 5. Let the function $v(x, t)$ strive to $g(x) \in L_{2}(\Gamma)$ under $t \rightarrow \infty$ in norm of the space $L_{2}(\Gamma)$ so that $\|v(t)-g\|_{L_{2}(\Gamma)} \rightarrow 0$ under $t \rightarrow \infty$ and $\int_{0}^{\infty}\left\|v^{\prime}(t)\right\|_{L_{2}(\Gamma)}^{2} d t<\infty$.

Then weak solution $y(v ; x, t)$ of the initial-boundary value problem (5), (6) strive to the weak solution $\theta$ of the problem (10) under $t \rightarrow \infty$ in norm of the space $L_{2}(\Gamma)$. 
P r o o f. First of all it should be noted that the weak solution $\theta(x)$ of the problem (10) is represented in the form of

$$
\theta(x)=\sum_{i=1}^{\infty} \frac{g_{i}}{\lambda_{i}} u_{i}(x), \quad g_{i}=\left(g, u_{i}\right)
$$

Indeed, $A \theta=\sum_{i=1}^{\infty} g_{i} u_{i}(x)=\sum_{i=1}^{\infty}\left(g, u_{i}\right) u_{i}(x)=g(x)$. The weak solution $y(v ; x, t)$ of problem $(5),(6)$ can be written as $y(v ; x, t)=y^{I}(v ; x, t)+y^{I I}(v ; x, t)$, where is

$$
\begin{gathered}
y^{I}(v ; x, t)=\sum_{i=1}^{\infty} \varphi_{i} e^{-\lambda_{i} t} u_{i}(x) \\
y^{I I}(v ; x, t)=\sum_{i=1}^{\infty} \int_{0}^{t} e^{-\lambda_{i}(t-\tau)} v_{i}(\tau) d \tau u_{i}(x), \quad v_{i}(\tau)=\left(v(\tau), u_{i}\right),
\end{gathered}
$$

it means

$$
\|y(v ; t)-\theta\|_{L_{2}(\Gamma)} \leqslant\left\|y^{I}(v ; t)\right\|_{L_{2}(\Gamma)}+\left\|y^{I I}(v ; t)-\theta\right\|_{L_{2}(\Gamma)} .
$$

Next, we have

$$
\left\|y^{I}(v ; t)\right\|_{L_{2}(\Gamma)}^{2}=\sum_{i=1}^{\infty}\left(\varphi, u_{i}\right)^{2} e^{-2 \lambda_{i} t} \leqslant e^{-2 \lambda_{1} t} \sum_{i=1}^{\infty}\left(\varphi, u_{i}\right)^{2}=e^{-2 \lambda_{1} t}\|\varphi\|_{L_{2}(\Gamma)}^{2} \rightarrow 0,
$$

when $t \rightarrow \infty$;

$$
\begin{gathered}
y^{I I}(v ; x, t)=\sum_{i=1}^{\infty} \frac{1}{\lambda_{i}}\left(v_{i}(t)-e^{-\lambda_{i} t} v_{i}(0)-\int_{0}^{t} e^{-\lambda_{i}(t-\tau)} v_{i}^{\prime}(\tau) d \tau\right) u_{i}(x), \\
\left\|y^{I I}(v ; t)-\theta\right\|_{L_{2}(\Gamma)}^{2}=\sum_{i=1}^{\infty} \frac{1}{\lambda_{i}^{2}}\left(\left(v_{i}(t)-\theta_{i}\right)-e^{-\lambda_{i} t} v_{i}(0)-\int_{0}^{t} e^{-\lambda_{i}(t-\tau)} v_{i}^{\prime}(\tau) d \tau\right)^{2} .
\end{gathered}
$$

Beginning with the Cauchy inequality, we get

$$
\begin{gathered}
\left\|y^{I I}(v ; t)-\theta\right\|_{L_{2}(\Gamma)}^{2} \leqslant 3 \sum_{i=1}^{\infty} \frac{1}{\lambda_{i}^{2}}\left(v_{i}(t)-\theta_{i}\right)^{2}+ \\
+3 \sum_{i=1}^{\infty} \frac{1}{\lambda_{i}^{2}} e^{-2 \lambda_{i} t} v_{i}^{2}(0)+3 \sum_{i=1}^{\infty} \frac{1}{\lambda_{i}^{2}}\left(\int_{0}^{t} e^{-\lambda_{i}(t-\tau)} v_{i}^{\prime}(\tau) d \tau\right)^{2} .
\end{gathered}
$$

Hence, when $t \rightarrow \infty$

$$
\begin{gathered}
\sum_{i=1}^{\infty} \frac{1}{\lambda_{i}^{2}}\left(v_{i}(t)-\theta_{i}\right)^{2} \leqslant \frac{1}{\lambda_{1}^{2}} \sum_{i=1}^{\infty}\left(v_{i}(t)-\theta_{i}\right)^{2}=\frac{1}{\lambda_{1}^{2}}\|v(t)-g\|_{L_{2}(\Gamma)}^{2} \rightarrow 0 \\
\sum_{i=1}^{\infty} \frac{1}{\lambda_{i}^{2}} e^{-2 \lambda_{i} t} v_{i}^{2}(0) \leqslant \frac{1}{\lambda_{1}^{2}} e^{-2 \lambda_{1} t} \sum_{i=1}^{\infty} e^{-2 \lambda_{i} t} v_{i}^{2}(0) \rightarrow 0
\end{gathered}
$$

It remains to evaluate the series of $\sum_{i=1}^{\infty} \frac{1}{\lambda_{i}^{2}}\left(\int_{0}^{t} e^{-\lambda_{i}(t-\tau)} v_{i}^{\prime}(\tau) d \tau\right)^{2}$. Let $t^{*}$ is a fixed number of interval $(0, t)$ such that $\int_{t^{*}}^{\infty}\left\|v^{\prime}(\tau)\right\|_{L_{2}(\Gamma)}^{2} d \tau<\epsilon \lambda_{1}^{3} / 2$, where $\epsilon$ is the arbitrarily given positive number. So as

$$
\begin{gathered}
\left(\int_{0}^{t} e^{-\lambda_{i}(t-\tau)} v_{i}^{\prime}(\tau) d \tau\right)^{2}=\left(\int_{0}^{\varsigma} e^{-\lambda_{i}(t-\tau)} v_{i}^{\prime}(\tau) d \tau+\int_{\varsigma}^{t} e^{-\lambda_{i}(t-\tau)} v_{i}^{\prime}(\tau) d \tau\right)^{2} \leqslant \\
\leqslant 2\left(\int_{0}^{\varsigma} e^{-\lambda_{i}(t-\tau)} v_{i}^{\prime}(\tau) d \tau\right)^{2}+2\left(\int_{\varsigma}^{t} e^{-\lambda_{i}(t-\tau)} v_{i}^{\prime}(\tau) d \tau\right)^{2},
\end{gathered}
$$


then, using the Cauchy-Schwartz inequality, we have

$$
\begin{aligned}
\left(\int_{0}^{t} e^{-\lambda_{i}(t-\tau)} v_{i}^{\prime}(\tau) d \tau\right)^{2} & \leqslant \frac{e^{-2 \lambda_{i}(t-\varsigma)}-e^{-2 \lambda_{i} t}}{\lambda_{i}} \int_{0}^{\varsigma} v_{i}^{\prime 2}(\tau) d \tau+\frac{1-e^{-2 \lambda_{i}(t-\varsigma)}}{\lambda_{i}} \int_{\varsigma}^{t} v_{i}^{\prime 2}(\tau) d \tau< \\
& <\frac{e^{-2 \lambda_{1}(t-\varsigma)}}{\lambda_{1}} \int_{0}^{\varsigma} v_{i}^{\prime 2}(\tau) d \tau+\frac{1}{\lambda_{1}} \int_{\varsigma}^{\infty} v_{i}^{\prime 2}(\tau) d \tau .
\end{aligned}
$$

Whence, granting of $\|v(t)\|_{L_{2}(\Gamma)}^{2}=\sum_{i=1}^{\infty} v_{i}^{2}(t)$, get

$$
\begin{gathered}
\sum_{i=1}^{\infty} \frac{1}{\lambda_{i}^{2}}\left(\int_{0}^{t} e^{-\lambda_{i}(t-\tau)} v_{i}^{\prime}(\tau) d \tau\right)^{2}<\frac{e^{-2 \lambda_{1}(t-\varsigma)}}{\lambda_{1}^{3}} \sum_{i=1}^{\infty} \int_{0}^{\varsigma} v_{i}^{\prime 2}(\tau) d \tau+\frac{1}{\lambda_{1}^{3}} \sum_{i=1}^{\infty} \int_{\varsigma}^{\infty} v_{i}^{\prime 2}(\tau) d \tau= \\
=\frac{e^{-2 \lambda_{1}(t-\varsigma)}}{\lambda_{1}^{3}} \int_{0}^{\varsigma}\left\|v^{\prime}(\tau)\right\|_{L_{2}(\Gamma)}^{2} d \tau+\frac{1}{\lambda_{1}^{3}} \int_{\varsigma}^{\infty}\left\|v^{\prime}(\tau)\right\|_{L_{2}(\Gamma)}^{2} d \tau< \\
<\frac{e^{-2 \lambda_{1}(t-\varsigma)}}{\lambda_{1}^{3}} \int_{0}^{\varsigma}\left\|v^{\prime}(\tau)\right\|_{L_{2}(\Gamma)}^{2} d \tau+\frac{\epsilon}{2} .
\end{gathered}
$$

By virtue of the convergence of integral $\int_{0}^{\infty}\left\|v^{\prime}(\tau)\right\|_{L_{2}(\Gamma)}^{2} d \tau$ (and thus limited $\int_{0}^{\varsigma}\left\|v^{\prime}(\tau)\right\|_{L_{2}(\Gamma)}^{2} d \tau$ when $\left.\varsigma<\infty\right)$ and when a sufficiently large $t_{0}$ correctly the inequality $\frac{e^{-2 \lambda_{1}(t-\varsigma)}}{\lambda_{1}^{3}} \int_{0}^{\varsigma}\left\|v^{\prime}(\tau)\right\|_{L_{2}(\Gamma)}^{2} d \tau<\frac{\epsilon}{2}, \quad t>t_{0}$, and hence the inequality $\left\|y^{I I}(v ; t)-\theta\right\|_{L_{2}(\Gamma)}^{2} \rightarrow 0$. The theorem is proved.

Conclusion. The approach presented the assertions of theorems $3-5$ it is possible may make use under obtain the conditions of stability (asymptotic stability) of the weak solutions of initial-boundary value problem (5), (6). This same approach can be applied to a problem in the direction of increasing dimensionality as the spatial variable $x\left(x \in \mathbb{R}^{n}\right.$ and the functions describing the state of the studied system [14]). The obtained results are fundamental in the problems of optimal control and stabilization of differential systems with delay [15-21].

\section{References}

1. Zhabko A. P., Tihomirov O. G. Chizhova O. N. O stabilizacii klassa sistem s proporcional'nym zapazdyvaniem [On stability to the class of systems with the proportional delay]. Vestnik of Saint Peterburg University. Applied Mathematics. Computer Science. Control Processes, 2018, vol. 14, iss. 2, pp. 165-172. https://doi.org/10.21638/11702/spbu10.2018.209 (In Russian)

2. Alexandrova I. V., Zhabko A. P. A new LKF approach to stability analysis of linear systems with uncertain delays. Automatica, 2018, vol. 91, pp. 173-178.

3. Provotorov V. V. Boundary control of a parabolic system with delay and distributed parameters on the graph. Intern. conference "Stability and Control Processes" in memory of V. I. Zubov (SCP). Saint Petersburg, Saint Petersburg University Publ., 2015, pp. 126-128.

4. Podvalny S. L., Provotorov V. V. The questions of controllability of a parabolic systems with distributed parameters on the graph. Intern. conference "Stability and Control Processes" in memory of V. I. Zubov (SCP). Saint Petersburg, Saint Petersburg University Publ., 2015, pp. 117-119.

5. Provotorov V. V. Boundary control of a parabolic system with distributed parameters on a graph in the class of summable functions. Automation and Remote Control, 2015, vol. 76. iss. 2, pp. 318-322.

6. Podvalny S. L., Provotorov V. V. Startovoe upravlenie parabolicheskoj sistemoj s raspredelennymi parametrami na grafe [Starting control of a parabolic system with distributed parameters on a graph]. Vestnik of Saint Petersburg University. Series 10. Applied Mathematics. Computer Science. Control Processes, 2015, iss. 3, pp. 126-142. (In Russian) 
7. Provotorov V. V., Gnilitskaya Yu. A. Granichnoe upravlenie volnovoi sistemoi v prostranstve obobshennyh reshenii na grafe [Boundary control of a wave systems in the space of the generalized solutions]. Vestnik of Saint Petersburg University. Series 10. Applied Mathematics. Computer Science. Control Processes, 2013, iss. 3, pp. 112-120. (In Russian)

8. Ladyzhenskaya O. A. Kraevye zadachi matematicheskoi fiziki [Boundary value problems of mathematical physics]. Moscow, Nauka Publ., 1973, 407 p. (In Russian)

9. Mihlin S. G. Lineinye uravnenija $v$ chastnyh proizvodnyh [Linear partial equation]. Moscow, Vysshaja shkola Publ., 1977, 431 p. (In Russian)

10. Provotorov V. V., Volkova A. S. Nachal'no-kraevie zadachi s raspredelennymi parametrami na grafe [Initial boundary value problems with distributed parameters on the graph]. Voronezh, Nauchnay kniga Publ., 2014, 188 p. (In Russian)

11. Provotorov V. V. Sobstvennye funkcii zadachi Shturma-Liuvillja na grafe-zvezde [Eigenfunctions of the Sturm-Liouville problem astar graph]. Mathematics, 2008, vol. 199, iss. 10, pp. 1523-1545. (In Russian)

12. Provotorov V. V., Provotorova E. N. Sintez optimal'nogo granichnogo upravlenija parabolicheskoi sistemy s zapazdyvaniem i raspredelennymi parametrami na grafe [Synthesis of optimal boundary control of parabolic systems with delay and distributed parameters on the graph]. Vestnik of Saint Petersburg University. Applied Mathematics. Computer Science. Control Processes, 2017, vol. 13, iss. 2, pp. 209-224. https://doi.org/10.21638/11701/spbu10.2017.207 (In Russian)

13. Lions J.-L. Some methods of solving non-linear boundary value problems. Paris, Dunod GauthierVillars, 1968, 587 p. (Russ. ed.: Lions J.-L. Nekotorye metody reshenia nelineinyh kraevyh zadach. Moscow, Mir Publ., 1972, 414 p.)

14. Provotorov V. V., Ryazhskikh V. I., Gnilitskaya Yu. A. Unique weak solvability of a nonlinear initial boundary value problem with distributed parameters in a netlike region. Vestnik of Saint Petersburg University. Applied Mathematics. Computer Science. Control Processes, 2017, vol. 13, iss. 3, pp. $264-277$. https://doi.org/10.21638/11701/spbu10.2017.304

15. Provotorov V. V., Provotorova E. N. Optimal control of the linearized Navier-Stokes system in a netlike domain. Vestnik of Saint Petersburg University. Applied Mathematics. Computer Science. Control Processes, 2017, vol. 13, iss. 4, pp. 428-441. https://doi.org/10.21638/11701/spbu10.2017.409

16. Aleksandrov A. Yu., Zhabko A. P. O stabilizacii recheniya odnogo klassa nelineinyh differencial'nyh sistem [On stability of solutions to one class of nonlinear difference systems]. Siberian Mathematical Journal, 2003, vol. 44, no. 6, pp. 951-958. (In Russian)

17. Aleksandrov A., Aleksandrova E., Zhabko A. Asymptotic stability conditions for certain classes of mechanical systems with time delay. WSEAS Transactions on Systems and Control, 2014, vol. 9, pp. 388-397.

18. Aleksandrov A., Aleksandrova E., Zhabko A. Asymptotic stability conditions of solutions for nonlinear multiconnected time-delay systems. Circuits Systems and Signal Processing, 2016, vol. 35, no. 10, pp. 3531-3554.

19. Karelin V. V. Shtrafnye funkcii v zadache upravleniya processom nabludeniya [Penalty functions in the control problem of an observation process]. Vestnik of Saint Petersburg University. Series 10. Applied Mathematics. Computer Science. Control Processes, 2010, iss. 4, pp. 109-114. (In Russian)

20. Kamachkin A. M., Yevstafyeva V. V. Oscillations in a relay control system at an external disturbance. Control Applications of Optimization 2000. Proceedings of the 11th IFAC Workshop, 2000, vol. 2, pp. 459-462.

21. Veremey E. I., Sotnikova M. V. Stabilizaciya plazmy na baze prognoza s ustoichivym lineinym priblizheniem [Plasma stabilization by prediction with stable linear approximation]. Vestnik of Saint Petersburg University. Series 10. Applied mathematics. Computer science. Control processes, 2011, iss. 1, pp. 116-133. (In Russian)

Received: January 21, 2019.

Accepted: March 15, 2019.

Author's information:

Aleksei P. Zhabko - Dr. Sci. in Physics and Mathematics, Professor; zhabko.apmath.spbu@mail.ru

Vyacheslav V. Provotorov - Dr. Sci. in Physics and Mathematics, Professor; wwprov@mail.ru

Olesya R. Balaban - bal-olesya@mail.ru 


\title{
Стабилизация слабого решения параболической системы с распределенными параметрами на графе
}

\author{
А. П. Жабко ${ }^{1}$, В. В. Провоторов ${ }^{2}$, О. Р. Балабан ${ }^{3}$
}

1 Санкт-Петербургский государственный университет, Российская Федерация, 199034, Санкт-Петербург, Университетская наб., 7-9

2 Воронежский государственный университет, Российская Федерация, 394006, Воронеж, Университетская пл., 1

3 Военно-воздушная академия им. профессора Н. Е. Жуковского и Ю. А. Гагарина, Российская Федерация, 396064, Воронеж, ул. Старых Большевиков, 54а

Для цитирования: Zhabko A. P., Provotorov V. V., Balaban O. R. Stabilization of weak solutions of parabolic systems with distributed parameters on the graph // Вестник Санкт-Петербургского университета. Прикладная математика. Информатика. Процессы управления. 2019. Т. 15. Вып. 2. C. 187-198. https://doi.org/10.21638/11702/spbu10.2019.203 (In English)

В многочисленных приложениях из-за сложности математических моделей приходится отказываться от использования обыкновенных дифференциальных уравнений в пользу рассмотрения эволюционных уравнений с частными производными. При этом чаще всего эволюционная задача изучается на конечном интервале изменения временной переменной. На практике, где можно решить задачу для произвольного конечного интервала изменения временной переменной, важно знать поведение решения, когда временная переменная стремится к бесконечности. Это связано с исследованием свойств стабилизации и устойчивости указанного решения. Именно такой случай является предметом изучения в настоящей работе: представлен анализ решения эволюционной системы с распределенными параметрами на графе при неограниченном возрастании временной переменной и связанный с ним вопрос о стабилизации решения. Изучая соответствующую начально-краевую задачу, мы выходим за рамки классических решений и обращаемся к слабым решениям задачи (т. е. проводим анализ начально-краевых задач в слабой постановке), отражающим более точно физическую сущность явлений и процессов. При этом выбор класса слабых решений, определяемого тем или иным функциональным пространством, обусловлен главным образом требованием сохранения теоремы существования и теоремы единственности на произвольном конечном интервале изменения временной переменной. В статье в основном применяются представление слабого решения в виде ряда (метод Фаедо-Галеркина со специальным базисом - системой собственных функций) и свойство компактности семейства приближенных решений (благодаря априорным оценкам).

Ключевые слова: эволюционная система параболического типа, распределенные параметры на графе, слабое решение, стабилизация слабого решения.

Контактная информация:

Жабко Алексей Петрович - д-р физ.-мат. наук, проф.; zhabko.apmath.spbu@mail.ru

Провоторов Вячеслав Васильевич - д-р физ.-мат. наук, проф.; wwprov@mail.ru

Балабан Олеся Руслановна - bal-olesya@mail.ru 